DOI: 10.12731/2070-7568-2017-2-61-79

УДК 321.015

\title{
НОРМАТИВНО-ПРАВОВЫЕ ОСНОВЫ ОБЕСПЕЧЕНИЯ НАЦИОНАЛЬНОЙ БЕЗОПАСНОСТИ РОССИЙСКОЙ ФЕДЕРАЦИИ НА СОВРЕМЕННОМ ЭТАПЕ
}

\author{
Иманов Д.Э.
}

В статье исследуются современное состояние нормативноправовой базы по обеспечению национальной безопасности Российской. Дается обзор основных нормативно-правовых актов, вводятся авторские трактовки терминов: «безопасность», «наџиональная безопасность».

Цель: на основе анализа формирования и эволющии нормативно-правовой базы РФ определить степень соответствия последней характеру вызовов и угроз в сфере глобальной и национальной безопасности.

Методология проведения работы: системный подход, экспертный анализ текстовой документальной информации, обобщение $и$ систематизачия статистических данных, сравнительный анализ.

Результаты: выработано авторское определение понятий «безопасность» и «национальная безопасность», прослежена эволючия законодательства РФ в области национальной безопасности, которое претерпело определённые качественные изменения, начиная от попыток обозначения вызовов и угроз в 90-е годы XX века и заканчивая нормативно-правовыми актами, охватывающими весь спектр современных проблем в сфере глобальной и национальной безопасности.

Область применения результатов: деятельность государственных институтов, обеспечивающих защиту национальных интересов России в современном мире.

Ключевые слова: безопасность; национальная безопасность; геополитика; суверенитет; территориальная иелостность. 


\section{NORMATIVE-LEGAL BASES OF ENSURING NATIONAL SECURITY OF THE RUSSIAN FEDERATION AT THE PRESENT STAGE OF DEVELOPMENT}

\section{Imanov D.E.}

The article examines the current state of the normative legal base for the national security of the Russian. Provides an overview of the main normative-legal acts, introduces the author's interpretation of the terms: "security", "national security".

Goal: based on the analysis of the formation and evolution of the regulatory framework of the Russian Federation to determine whether the last character of challenges and threats in global and national security.

Methodology: a systematic approach, expert analysis of textual documentary information, compilation and systematization of statistical data, comparative analysis.

Results: the developed author's definition of "security" and "national security", traces the evolution of the legislation of the Russian Federation in the field of national security, which has undergone certain qualitative changes, ranging from attempts to denote challenges and threats in the 90-ies of the twentieth century to the normative-legal acts, covering the whole range of contemporary issues in global and national security.

The scope of the results: the activities of state institutions that ensure the protection of national interests of Russia in the modern world.

Keywords: security; national security; geopolitics; sovereignty; territorial integrity.

Понятие «национальная безопасность» является достаточно широким, размытым и дискуссионным. Исследователи данного феномена вкладывают в его дефиниции всевозможное содержание, подчёркивая различные аспекты его проявления: от правовых до институциональных. Чтобы обстоятельно исследовать данный фе- 
номен необходимо ввести понятия «безопасность» и «национальная безопасность», дать им определения, раскрыть их сущность, а также рассмотреть законодательство РФ, затрагивающее вопросы обеспечения национальной безопасности.

Общепринятой дефиниции для данного понятия существует, поскольку для него, как и для любого другого социального феномена, характерна многосторонность и многофакторность. Оно применимо в различных областях общественной жизни: в военной, в политической, в экономической, в культурно-просветительской и собственно социальной, что объясняет многообразие подходов к трактовке данного понятия. Научное сообщество согласно с тем, что до сих пор не существует общепризнанного определения безопасности [10] и не утратили актуальность попытки сформировать рабочее определение для дальнейшего использования в рамках данного исследования.

Согласно толковому словарю В.И. Даля под безопасностью понимается отсутствие опасности кому-либо и/или чему-либо со стороны кого-либо и/или чего-либо, сохранность, надёжность [6]. В.И. Даль толкует безопасность как пассивную категорию (отсутствие опасности кому-либо и/или чему-либо со стороны кого-либо и/или чего-либо), а словарь С.И. Ожегова рассматривает данное понятие как пассивно-активную категорию: состояние, при котором не угрожает опасность (пассивная), существует защита от опасности (активная) [7]. Данные выше определения носят универсальный характер и подходят для трактовки безопасности применительно к той или иной сфере общественных отношений. Если говорить о сугубо социально-политической трактовке безопасности, то следует обратиться к специализированной литературе.

Согласно социологическому словарю академика РАН Г.В. Осипова и доктора философских наук, профессора Л.Н. Москвичева безопасность трактуется как состояние, тенденции развития (включая скрытые) и условия жизнедеятельности общества, его структуры, ценности и соответствующие им институты, при которых обеспечивается сохранение их качественной определенности 
с объективно обусловленными эволюционными изменениями в ней и свободное, соответствующее её собственной природе и ею определяемое функционирование [8]. Иначе говоря, под безопасностью понимается не мифическое «отсутствие опасности», которое, по словам авторов, даже теоретически смоделировать невозможно, а способность общества сохранять свою идентичность в условиях объективных эволюционных преобразований. Безопасность предполагает не мир без опасностей, а его способность к адекватному ответу на существующие и потенциальные вызовы исторического процесса и непосредственные угрозы стабильности и развитию как всему человечеству, так и его отдельным группам. Рассматриваемое нами понятие находит своё отражение и в законодательстве РФ. Например, Федеральный закон «О безопасности» от 1992 года (в настоящее время утратил силу в данной редакции) трактует безопасность как состояние защищенности жизненно важных интересов личности, общества и государства от внутренних и внешних угроз [1].

Учитывая вышеприведённые дефиниции, можно говорить о том, что под безопасностью в социальном отношении (т.е. применительно к обществу) следует понимать такое состояние социума, при котором его общественные отношения, соответствующие им институты и ценности не только обеспечивают стабильное функционирование (позволяюеее сохранить уникальную идентичность) и эволюционное (бескризисное и бесконфликтное, насколько это возможно) развитие (на базе научно-технического прогресса) этого общества, но и имеют необходимые силы и средства для прогнозирования и своевременного отражения реальных и гипотетических попыток (как внутренних, так и внешних) его дестабилизации. Приведённое выше определение автор статьи использует в качестве рабочего в данном исследовании.

Обратимся к национальной безопасности. Общепринятого подхода к определению данного понятия также не существует, что объясняется сложностью и многогранностью этого социального феномена. Сложность заключается в том, что даже в суждениях 
по поводу того, что понимать под эпитетом «национальный», наблюдается несогласованность позиций. Несмотря на огромное количество подходов к трактовке приведённого выше эпитета, в целом дискуссия в научном сообществе разворачивается вокруг двух основных точек зрения. В первом случае исследователи трактуют национальную безопасность достаточно узко, понимая под ней защищённость институтов государственной власти в первую очередь перед внешними угрозами и способность отстаивать свой суверенитет. Впервые термин «национальная безопасность» появился в послании Президента США Т. Рузвельта Конгрессу в 1904 году, который, по словам доктора политических наук, профессора А.В. Копылова, употреблялся в смысле обороны, а не интеграции внешней, внутренней и военной политики. [13]. Одним из ярких примеров в этом отношении, по словам главного научного сотрудника Института мировой экономики и международных отношений (ИМЭМО) РАН, доктора исторических наук В.Л. Шейниса, является Советский Союз, во времена которого «... безопасность никогда не называлась национальной и всегда интерпретировалась как безопасность государства (безопасность общества и личности выступали в лучшем случае как её производные) ...» [14, с. 141]. Представители данного направления учёного сообщества объявляют идентичными национальную и государственную безопасность. Эпитеты «государственный» и «национальный» в этом случае являются синонимичными. Однако, справедливости ради, стоит отметить, что такая позиция на уровне реальной политики государств (в том числе в нормативно-правовых актах стран) сегодня практически не встречается. Хотя некоторые политические режимы, в особенности авторитарного и тоталитарного толка, по-прежнему считают, что защищённость институтов власти от внешних угроз (в первую очередь военной) и государственный суверенитет автоматически подразумевают безопасность общества и личности, которые зачастую отождествляются с государством.

Что касается второго подхода к национальной безопасности, то её рассматривают в широком смысле, не только как государствен- 
ную безопасность, но и как безопасность общества и личности, причём не только внешнюю, но и внутреннюю. Такая постановка вопроса особенно характерна для развитых демократических государств. Данная точка зрения находит всё больше откликов в мире, постепенно становясь господствующей. Современные определения понятия «национальная безопасность» вполне подтверждают это. Например, «Новейший политологический словарь» Д.Е. Погорелого, В.Ю. Фесенко и К.В. Фелиппова трактует национальную безопасность как совокупность внутренних и внешних условий, выполнение которых обеспечивает стабильное политическое, социально-экономическое и духовно-культурное развитие общества и личности, а также независимость, защиту суверенитета и территориальную целостность государства [9]. Характерны в этом отношении официальные документы и законодательство РФ.

Впервые термин «национальная безопасность» в официальных документах постсоветской России появляется в Послании по национальной безопасности Президента Российской Федерации Федеральному Собранию от 13 июня 1996 года. В документе отмечается, что национальная безопасность подразумевает безопасность и защиту интересов личности, общества и государства от противоправных посягательств, общественно опасных деяний, социальных конфликтов, чрезвычайных ситуаций, вызванных стихийными бедствиями, авариями и катастрофами. Трактовка достаточно размытая. Непонятно, в частности, что именно понимается под словосочетанием «противоправные посягательства», какой характер они имеют (внутренний, внешний или совокупный), со стороны кого возможны реальные или потенциальные посягательства и самое главное - на что они могут быть направлены. Ответов на эти вопросы данное Послание нам не даёт.

Объяснений этому можно найти несколько. Размытость понятий в официальных документах того времени объясняется полной перекройкой с подачи Запада всех общественных ценностей с соответствующими им социальными институтами и нормативноправовой базой. Это привело, помимо других, более болезненных 
социальных последствий, к замене понятий и терминов, которыми оперировала общественность, наука и политическая власть, а также к появлению новых. В числе последних, как уже отмечалось выше, оказалась и национальная безопасность. Именно отсутствием опыта можно частично обосновать размытость формулировок в официальных документах того времени, хотя такая позиция является немного наивной. Более реалистичным объяснением представляется тот факт, что российское руководство послесоветского периода длительное время лелеяло мечту о равноправном партнёрстве с Западом после серии колоссальных уступок сначала со стороны СССР, а затем и новой России. Иллюзии о возможности равноправного партнёрства с Европой и США после оказания ряда существенных односторонних уступок со стороны политического руководства СССР привели к тому, что государство сначала утратило статус второй (наравне с США) мировой сверхдержавы и практически полностью лишилось поддержки и влияния в странах так называемого социалистического блока, а позже потеряло треть своих территорий. Особенно болезненным следствием проводимой в те годы руководством страны политики стала утрата Белоруссии и Украины. Серьёзным геополитическим поражением для России явилось значительное ограничение доступа к Чёрному, Каспийскому и Балтийскому морям. Многовековые экономические, политические, военные, культурные, социальные, семейные связи значительно ослабли. Распад единого государства стал личной трагедией для каждого советского человека. Однако «...крупнейшая геополитическая катастрофа века...», как позже охарактеризовал развал СССР Президент РФ В.В. Путин, не только не привела к политическому прозрению властвующей на тот момент политической элиты, но и ещё больше укрепило её веру в то, что после такого геополитического ослабления России Запад просто обязан распахнуть свои двери и принять её в лоно западной цивилизации. По словам 3. Бжезинского «...nосле распада СССР позищия Ельцина отражала всегда лелеемую, но никогда полностью не достигавшую успеха концепциию русской политической мысли, продвигаемую и отстаи- 
ваемую так называемыми “западниками”: Россия - часть западного мира - является неотъемлемой частью Запада и должна как можно больше подражать ему в своём развитии. Эта точка зрения продвигалась самим Ельцинымм и его министром иностранных дел Козыревым, при этом Президент России постоянно и весьма недвусмысленно осуждал русское имперское наследие...» [5, с. 122]. Именно поэтому, по-видимому, в Послании 1996 года «противоправное посягательство» никак не конкретизировалось, потому как в условиях “зрелого стратегического партнёрства” с Западом, в которое наивно верило политическое руководство России после геополитического самоубийства, рассматривать Европу и США в качестве реальной или потенциальной угрозы было невозможно.

Следующим документом, который рассматривал вопросы национальной безопасности, стала Концепция национальной безопасности Российской Федерации, утверждённая Указом Президента РФ от 17 декабря 1997 г. №1300 (в редакции Указа Президента Российской Федерации от 10 января 2000 г. №24) [2]. Данный документ является более структурированным и содержательным в сравнении с Посланием от 1996 года. В преамбуле Указа отмечается, что национальная безопасность подразумевает обеспечение в Российской Федерации безопасности личности, общества и государства от внешних и внутренних угроз во всех сферах жизнедеятельности. Ключевым отличием Послания 1996 года от Концепции 1997 года (в редакции 2000 года) стала конкретизация характера угроз национальной безопасности. Документ признаёт наличие как внешних вызовов российскому государству, обществу и личности, так и говорит о потенциальных внутренних проблемах. Переосмысление реальных и потенциальных угроз России во многом связано со сменой политического руководства страны, ведь Указ от 2000-го года подписывалась уже В.В. Путиным.

Концепция национальной безопасности Российской Федерации определяет две взаимоисключающие тенденции развития современного мира. Первая заключается в том, что международные отношения стремятся к многополярности: усиливаются взаимные эко- 
номические, политические, социальные и культурные взаимосвязи между государствами, расширяется взаимодействие между народами и его отдельными представителями, упрочняются образовательные и просветительские международные контакты. Другими словами, страны становятся более взаимозависимыми и открытыми. Однако в документе упоминается и другая, противоположная первой, тенденция, которая заключается в стремлении создать такую структуру международных отношений, доминировать в которой будут США и её сателлиты. Вопросы мирового значения, в том числе и международной безопасности, в такой системе будут решаться в одностороннем порядке и преимущественно военными средствами в обход основополагающих норм и принципов международного права. Мир, в случае упрочения последней тенденции, может стать однополярным. Сегодня можно без преувеличения говорить о том, что 15 лет, прошедших с момента принятия Концепции в последней редакции, подтвердили тревожный тренд стремления США к статусу мирового гегемона, а осторожные попытки России к воссоединению исконных земель вызвали жесткий отпор. Как отмечает проф. И.Л. Морозов: «Воссоединение Крыла с Россией в марте 2014 2. было расиенено лидерами стран НАТО как начало процесса геополитической интеграции постсоветского пространства под эгидой Москвы и укрепления международного влияния Президента Российской Федераичи В.В. Путина» [12, с. 112].

В утвержденной в начале президентства В.В. Путина Концепции национальной безопасности уже прослеживается четкая классификация внутренних и внешних угрозах национальной безопасности России. Среди первых отмечаются нижеследующие.

1. В экономике: масштабные сокращения валового внутреннего продукта, снижение инвестиционно-инновационной активности и научно-технического потенциала, стагнация аграрного и промышленного производства, рост внутреннего и внешнего долга, преобладание сырьевой и энергетической составляющей в экспорте и товаров первой необходимости и продовольствия - в импорте, рост безработицы. 
2. В науке: значительное снижение технико-технологического потенциала государства, сворачивание стратегических научныхисследовательских программ и проектов, утечка кадров и интеллектуальной собственности за границу, деградация наукоёмких производственных цепочек, усиление иностранно технико-технологической зависимости и, как следствие, подрыв обороноспособности государства.

3. В военной сфере: затянувшиеся и малопродуктивные процессы реформирования и реорганизации армии и ВПК, недостаточные объёмы финансирования государственной обороны, критически низкая боевая и оперативная подготовка ВС, недопустимо низкий процент укомплектованности войск современными видами вооружений, нерешённость социально-бытовых вопросов военнослужащих.

4. В социальной сфере: катастрофическая дифференциация общества на узкую прослойку богатых и широкие слои бедных, девальвация духовных ценностей, шовинизм и этноцентризм, сепаратизм, неконтролируемая миграция, коррупция, криминализация общественных отношений, рост потребления алкоголя и наркотических средств, резкое сокращение темпов воспроизводства населения и средней продолжительности жизни, ослабление института семьи.

5. В правовой сфере: несоблюдение принципов приоритета Конституции РФ над иными нормативно-правовыми актами, недостаточная координация между различными уровнями власти и управления, правовой нигилизм, отток квалифицированных кадров из правоохранительных органов, сращивание отдельных элементов законодательной, исполнительной и судебной власти с преступным сообществом.

К угрозам международного характера (внешним) Концепция относит нижеследующие.

1. Стремление некоторых государств и межгосударственных объединений сузить роль ООН и ОБСЕ как действенных механизмов поддержания глобальной безопасности; 
2. Расширение НАТО на Восток и, как следствие, вероятность расположения в непосредственной близости от государственных границ РФ военных баз иностранных государств и соответствующих воинских формирований.

3. Переход НАТО к практике силовых (военных) акций вне зоны ответственности и географического расположения альянса, а также без соответствующих решений Совбеза ООН.

4. Наращивание наиболее развитыми странами военных расходов, разработка новейших средств вооружения и, как следствие, всё шире разворачивающаяся гонка вооружений.

5. Распространение международного терроризма и экстремизма.

6. Распространение оружия массового поражения, средств его доставки и потенциальная возможность завладения им международными вооружёнными формированиями экстремистского и террористического толка.

7. Ослабление института Содружества независимых государств, последующее сворачивание интеграционных проектов и ослабление уже существующих связей на постсоветском пространстве.

8. Возникновение новых или эскалация существующих конфликтов как на границе Российской Федерации или стран СНГ, так и внутри этого объединения.

9. Действие иностранных спецслужб и аффилированных с ними общественных организаций, преследующих самые разные цели, на территории Российской Федерации.

10. Притязания на территориальную целостность и суверенитет Российской Федерации.

11. Попытки противодействия становлению России как одного из центров многополярного мира, а также содействие ослаблению позиции РФ в Европе, на Ближнем Востоке, на Кавказе, в Центральной Азии и Азиатско-Тихоокеанском регионе.

Отдельно в документе прописываются информационные угрозы. Подчёркивается стремление некоторых государств к доминированию в глобальном информационном пространстве, признаётся планомерное и настойчивое вытеснении РФ не только с внешнего 
информационного поля, но и внутреннего, что говорит о существенных упущениях государства в вопросах информационно-просветительской политики. Концепция официально признаёт наличие информационных войн, которые предусматривают наличие у иностранных государств средств опасного воздействия на информационные сферы других стран мира с целью нарушения нормального функционирования информационных и телекоммуникационных систем, что ставит под сомнение сохранность информационных ресурсов, а также актуализирует проблему возможного несанкционированного доступа к ним.

Следующими документами, касающимися вопросов национальной безопасности России, стали Стратегия национальной безопасности Российской Федерации до 2020 года, изложенная в Указе Президента РФ от 12 мая 2009 г. №537 (в редакции Указа Президента РФ от 1 июля 2014 года №483) [3], а затем пришедшая ей на смену Стратегия национальной безопасности Российской Федерации, изложенная в Указе Президента РФ от 31 декабря 2015 г. №683 [4]. Согласно Стратегии под национальной безопасностью понимается состояние защищенности личности, общества и государства от внутренних и внешних угроз, которое позволяет обеспечить конституционные права, свободы, достойные качество и уровень жизни граждан, суверенитет, территориальную целостность и устойчивое развитие Российской Федерации, оборону и безопасность государства. Стратегия вслед за Концепцией говорит о ключевых тенденциях развития мировой политики и международных отношений. Помимо двух вышеперечисленных, добавляется третий вектор развития ситуации на международной арене. В документе оговаривается долгосрочная перспектива обострения борьбы за обладание ключевыми природными ресурсами, в особенности водными и энергетическими. Речь идёт, в первую очередь, о Ближнем Востоке, Баренцевом море и других районах Арктики, а также о Каспийском море и Центральной Азии. Очевидно, что потенциальные конфликты вокруг этих территорий автоматически ставят национальную безопасность России под угрозу, так как всё вышеперечисленное 
либо является непосредственной частью Российской Федерации, либо граничит с ней, либо входит в зону её государственных интересов. В этом смысле развитие последней тенденции напрямую зависит от победы одной из первых двух. Не поддаётся сомнению тот факт, что решать ресурсные и территориальные вопросы в условиях многополярности проще, тогда как у однополярного мира соблазн решить все споры силой будет больше. Если говорить о конкретных угрозах национальной безопасности РФ, то согласно Стратегии таковыми являются нижеследующие.

1. В сфере национальной обороны: политика отдельных стран, направленная на достижение доминирования над остальным миром в сфере стратегических ядерных сил, высокоточных информационных и иных высокотехнологичных средствах борьбы, стратегических неядерных сил, и как следствие, разворачивающийся новый виток гонки вооружений; одностороннее развёртывание глобальной системы ПРО; милитаризация космоса; распространение биологических, химических, ядерных технологий и потенциальная возможность завладения ими интернациональными вооружёнными формированиями экстремистского и террористического толка; нивелирование международных договоров по сокращению и ограничению вооружений; действия, преследующие нарушение устойчивого функционирования систем: военного и государственного управления, контроля космического пространства, раннего предупреждения о ракетном нападении, контроля атомной и химической промышленности, функционирования стратегических ядерных сил, атомной энергетики, а также объектов хранения ядерных боеприпасов.

2. В сфере государственной и общественной безопасности: действие иностранных спецслужб и аффилированных с ними общественных организаций или отдельных лиц, преследующих самые разные цели, на территории Российской Федерации; противоправные действия этнических, религиозных, националистических и иных организаций и объединений, направленная на деструкцию единства и территориальной целостности РФ, дестабилизацию со- 
циально-экономического и внутриполитического положения в государстве; деятельность интернациональных преступных сообществ и группировок, террористических организаций, связанная с незаконным оборотом наркотиков и психотропных препаратов, взрывчатых веществ, оружия и боеприпасов к нему; сохраняющийся рост числа противоправных посягательств, направленных против личности, общества и государства, общественной и экономической безопасности, собственности; коррупция; недостаточный уровень развития инфраструктуры погранзастав и технико-технологической оснащенности пограничных пунктов.

3. В сфере качества жизни российских граждан: периодические кризисы мировой и региональных финансово-экономических систем, нарастание конкурентной борьбы за становящиеся всё более дефицитными продовольственные, водные и сырьево-энергетические ресурсы, всё более увеличивающееся отставание в развитии передовых технико-технологических укладов, что в совокупности повышает стратегические риски зависимости от внешних конъюнктур.

4. В сфере экономики: экспортно-сырьевая модель национальной экономики; снижение экономической конкурентоспособности России и её высокая зависимость от внешних факторов; утрата контроля над источниками национальных ресурсов; деструкция материально-технической базы энергетики и промышленности; непропорциональное развитие субъектов федерации; всё более прогрессирующий недостаток трудовых ресурсов в некоторых отраслях экономики; слабая защищённость и достаточно низкая устойчивость национальной системы финансов; сохранение коррупциогенных факторов и криминализация финансово-хозяйственных связей; неконтролируемая миграция; низкая эффективность регулирования экономики со стороны государства; замедление экономического роста; усиление недобросовестной конкуренции и принятие дискриминационных мер по отношению к РФ, а также кризисы мировой экономики.

5. В сфере науки, технологий и образования: увеличивающаяся зависимость от иностранных поставок научных приборов и обору- 
дования, стратегических материалов; несанкционированная утечка за границу конкурентоспособных отечественных технологий; неправовые односторонние санкционные ограничения по отношению к научно-исследовательским и культурно-образовательным организациям РФ; недостаточная разработанность нормативно-правовой базы и слабая мотивация в сфере инновационно-промышленной политики; низкие уровень социальной защищённости педагогического, инженерно-технического и профессорско-преподавательского состава и качество образования всех ступеней.

6. В сфере здравоохранения: потенциальные масштабные эпидемии и пандемии; распространение ВИЧ и туберкулёза, алкоголизма и наркомании; рост доступности психотропных и психоактивных препаратов; низкий уровень эффективности системы медицинского страхования и качества подготовки и переподготовки специалистов в области здравоохранения; недостаточные социальные гарантии медицинских работников; слабое финансирование высокотехнологичной медицины; незавершённость процессов принятие соответствующей нормативно-правовой базы здравоохранения;

7. В сфере культуры: широкое распространение продукции массовой культуры, направленной на маргинализацию общества; противоправные действия по отношению к объектам культуры; попытки пересмотра истории России, её роли в мировых процессах; пропаганда насилия и вседозволенности, религиозной, расовой и этнической нетерпимости.

Однако вступившая в силу новая Концепция национальной безопасности России получила неоднозначную оценку со стороны специалистов. Например, российские политологи обращают внимание на следующий факт: «...nринятая 31 декабря 2015 г. новая Стратегия нацчиональной безопасности Российской Федерацуии хотя содержательно и является шагом вперед в сравнении с предшествуюшим аналогом, но по-прежнему (очевидно, по соображениям политической целесообразности) не заостряет внимания на ряде новейших вызовов и угроз современного мира (украинском гео- 
политическом кризисе, внутреннем генезисе терроризма в России и т. ә.)» [11, с. 12].

Исходя из всего вышесказанного, можно резюмировать, что законодательство РФ в области национальной безопасности претерпело определённую эволюцию, начиная от робких (без конкретизации, классификации и со “сглаживанием углов”) попыток обозначения вызовов и угроз безопасности государства в 90-е годы и заканчивая современными нормативно-правовыми актами, охватывающими широкий спектр проблем. Под национальной безопасностью современного государства необходимо понимать такое состояние личности, общества и государства, при котором не только обеспечиваются стабильное функционирование государства, динамичное развитие общества и достойное существование личности, но и существуют необходимые силы и средства, позволяющие эффективно прогнозировать потенциальные и своевременного отражать реальные (как внутренние, так и внешние) угрозы, направленные на дестабилизацию существующего положения.

\section{Список литературы}

1. Российская Федерация. Законы. О безопасности: федер. закон от 5 марта 1992 г. №2446-I (ред. от 26.06.2008) / Российская Федерация. Законы [Электронный ресурс]. http://svr.gov.ru/svr_today/doc04.htm (дата обращения: 21.12.2016).

2. Российская Федерация. Президент (1996-1999; Б.Н. Ельцин). Об утверждении Концепции национальной безопасности Российской Федерации [Электронный ресурс]: указ Президента РФ от 17 декабря 1997 г. №1300 (ред. от 10.01.2000) / Российская Федерация. Президент (1996-1999; Б.Н. Ельцин). http://kremlin.ru/acts/ bank/14927 (дата обращения: 22.12.2016).

3. Российская Федерация. Президент (2008 - 2012; Д.А. Медведев). О стратегии национальной безопасности Российской Федерации [Электронный ресурс]: указ Президента РФ от 12 мая 2009 г. №537 (ред. от 01.06.2014) / Российская Федерация. Президент (2008- 
2012; Д.А. Медведев). http://www.consultant.ru/document/cons_doc_ LAW_87685/(дата обращения: 22.12.2016).

4. Российская Федерация. Президент (2012-2018; В.В. Путин). О стратегии национальной безопасности Российской Федерации [Электронный ресурс]: указ Президента РФ от 31 декабря 2015 г. №683 / Российская Федерация. Президент (2012-2018; В.В. Путин). http://www.consultant.ru/document/cons_doc_LAW_191669/(дата обращения: 22.12.2016).

5. Бжезинский 3. Великая шахматная доска. Господство Америки и его геостратегические императивы. М.: АСТ, 2014. 702 с.

6. Даль В.И. Толковый словарь живого великорусского языка. М.: Общество любителей российской словесности, 1863. Ч.1. 627 с.

7. Ожегов С.И. Толковый словарь русского языка. М.: Оникс, 2011. $736 \mathrm{c}$.

8. Осипов Г.В. Социологический словарь. М.: Норма, 2008. 608 с.

9. Погорелый Д.Е. Новейший политологический словарь. Ростов н/Д: Феникс, 2010. 318 с.

10. Волочаева О.Ф. Информационно-культурная составляющая системы невоенных факторов национальной безопасности // Власть. 2013. № 2. C. 50-52.

11. Морозов И.Л. Новая стратегия национальной безопасности России и меняющийся мир // Общество: политика, экономика, право. 2016. № 4. C. 10-12.

12. Морозов И.Л. Геополитическая безопасность современной России // Теория и практика общественного развития. 2015. № 8. С. 112 114.

13. Копылов А. В. О генезисе и сущности понятия «национальная безопасность» // Военная мысль. 2014. №11. С. 47-56.

14. Шейнис В.Л. Национальная безопасность России. Испытание на прочность // Политические исследования. 2009. №5. С. 141-148.

\section{References}

1. Rossiyskaya Federatsiya. Zakony. O bezopasnosti: feder. zakon ot 5 marta 1992 g. №2446-I (red. ot 26.06.2008) [About security: the Fe- 
deral law of 5 March 1992 n 2446-I (as amended on 26.06.2008)]. http:// svr.gov.ru/svr_today/doc04.htm (accessed 21.12.2016).

2. Rossiyskaya Federatsiya. Prezident (1996-1999; B.N. El'tsin). Ob utverzhdenii Kontseptsii natsional'noy bezopasnosti Rossiyskoy Federatsii: ukaz Prezidenta RF ot 17 dekabrya 1997 g. №1300 (red. ot 10.01.2000) [On approval of the national security Concept of the Russian Federation: the decree of the President of the Russian Federation of 17 December 1997 №1300 (ed. by 10.01.2000)]. http://kremlin.ru/acts/ bank/14927 (accessed 22.12.2016).

3. Rossiyskaya Federatsiya. Prezident (2008-2012; D.A. Medvedev). O strategii natsional'noy bezopasnosti Rossiyskoy Federatsii: ukaz Prezidenta RF ot 12 maya 2009 g. №537 (red. ot 01.06.2014) [ On the national security strategy of the Russian Federation: the decree of the President of the Russian Federation 12 may 2009 No. 537 (as amended on 01.06.2014)]. http://www.consultant.ru/document/cons_doc_ LAW_87685/(accessed 22.12.2016).

4. Rossiyskaya Federatsiya. Prezident (2012-2018; V.V. Putin). O strategii natsional'noy bezopasnosti Rossiyskoy Federatsii: ukaz Prezidenta RF ot 31 dekabrya 2015 g. № 683 [On the national security strategy of the Russian Federation: the decree of the President of the Russian Federation from December 31, 2015 No. 683]. http:// www.consultant.ru/document/cons_doc_LAW_191669/(accessed 22.12.2016).

5. Bzhezinskiy Z. Velikaya shakhmatnaya doska. Gospodstvo Ameriki i ego geostrategicheskie imperativyy [The Grand chessboard. The domination of America and its geostrategic imperatives]. Moscow: AST, 2014. 702 p.

6. Dal' V.I. Tolkovyy slovar' zhivogo velikorusskogo yazyka [Explanatory dictionary of the living great Russian language]. Moscow: Obshchestvo lyubiteley rossiyskoy slovesnosti, 1863. Ch.1. 627 p.

7. Ozhegov S.I. Tolkovyy slovar' russkogo yazyka [Explanatory dictionary of the Russian language]. Moscow: Oniks, 2011. 736 p.

8. Osipov G.V. Sotsiologicheskiy slovar' [Sociological dictionary]. Moscow: Norma, 2008. 608 p. 
9. Pogorelyy D.E. Noveyshiy politologicheskiy slovar' [The latest political dictionary]. Rostov n/D: Feniks, 2010. 318 p.

10. Volochaeva O.F. Informatsionno-kul'turnaya sostavlyayushchaya sistemy nevoennykh faktorov natsional'noy bezopasnosti [Information and cultural component of the system of non-military factors of national security]. Vlast'. 2013. № 2, pp. 50-52.

11. Morozov I.L. Novaya strategiya natsional'noy bezopasnosti Rossii i menyayushchiysya mir [The new strategy of national security of Russia and the changing world]. Obshchestvo: politika, ekonomika, pravo. 2016. № 4, pp. 10-12.

12. Morozov I.L. Geopoliticheskaya bezopasnost' sovremennoy Rossii [Geopolitical security of modern Russia]. Teoriya i praktika obshchestvennogo razvitiya. 2015. № 8, pp. 112-114.

13. Kopylov A.V. O genezise i sushchnosti ponyatiya «natsional'naya bezopasnost'» [On the Genesis and nature of "national security"]. Voennaya mysl'. 2014. №11, pp. 47-56.

14. Sheynis V.L. Natsional'naya bezopasnost' Rossii. Ispytanie na prochnost' [Russia's national security. A test of strength]. Politicheskie issledovaniya. 2009. №5, pp. 141-148.

\section{ДАННЫЕ ОБ АВТОРЕ}

Иманов Джамиль Эльчинович, магистрант

Волгоградский институт управления ФГБОУ ВО «Российская академия народного хозяйства и государственной службы при Президенте Российской Федераџии» ул. Гагарина 8, г. Волгоград, 400131, Российская Федерация d-imanov@mail.ru

\section{DATA ABOUT THE AUTHOR}

\section{Imanov Dzhamil Elchinovich, Master Student}

Volgograd Institute of management of the Russian Presidential Academy of National Economy and Public Administration 8, Gagarin Str., Volgograd, 400131, Russian Federation d-imanov@mail.ru 